\title{
Sudden Death Documented During 24-Hour Holter Monitoring
}

\author{
Morte Súbita Documentada Durante Monitorização com Holter 24 Horas \\ Kárila Scarduelli Luciano ${ }^{1, *}$, Rafael Zoppi Campane ${ }^{1}$, Rafaela Louise Sales ${ }^{1}$, Alessandra Kraus, \\ Erden Ramirez Pestana ${ }^{1}$, Rafael de March Ronsoni ${ }^{1}$
}

ORCID IDS

Luciano KS (DD https://orcid.org/0000-0002-5210-8414

Campane RZ (D) https://orcid.org/0000-0001-7773-2929

Sales RL (D) https://orcid.org/0000-0002-3831-3016

\begin{abstract}
A 50-year-old female patient admitted for etiological syncope investigation. A 24-hour Holter was installed where the record showed the mechanism of sudden cardiac death. Sudden bradycardia caused by paroxysmal atrioventricular block led to torsades de pointes, ventricular fibrillation and death. This case shows the importance of Holter in the chronology of arrhythmic events that lead to sudden death and highlights a poorly reported event - the occurrence of cardiac death during 24-hour Holter monitoring.
\end{abstract}

KEYWORDS: Sudden death; Ventricular fibrillation; Ambulatory electrocardiography.

\author{
Kraus A (iD https://orcid.org/0000-0002-4555-5881 \\ Pestana ER (D) https://orcid.org/0000-0003-1824-8824 \\ Ronsoni RM (D) https://orcid.org/0000-0001-7135-9844
}

\section{RESUMO}

Paciente do sexo feminino, 50 anos, internada para investigação etiológica de síncope. Instalado Holter de 24 horas onde o registro mostrou o mecanismo da morte súbita cardíaca. A bradicardia súbita causada por bloqueio atrioventricular paroxístico levou ao torsades de pointes, à fibrilação ventricular e ao óbito. Este caso demonstra a importância do Holter na cronologia de eventos arrítmicos que levam à morte súbita e destaca um evento pouco relatado - a ocorrência de morte cardíaca durante a monitorização com Holter 24 horas.

PALAVRAS-CHAVE: Morte súbita; Fibrilação ventricular; Eletrocardiografia ambulatorial.

1. Hospital Regional Hans Dieter Schmidt - Setor de Cardiologia - Joinville (SC), Brazil.

Received: Dec. 01, 2019 | Accepted: Feb. 03, 2020

*Correspondence author: karilasl@gmail.com

Section Editor: José Tarciso Medeiros de Vasconcelos 


\section{INTRODUCTION}

The prevalence of sudden cardiac death (SCD) in 24-hour Holter monitoring (H24) is not known, but it is estimated to be a rare event. In an unregistered SCD, it is difficult to accurately identify the primary arrhythmia responsible for the event based only on the heart rate obtained by the emergency team, because an arrhythmia can start with one mechanism and degenerate into another ${ }^{1,2}$

\section{CASE REPORT}

Female patient, 50 years old, former smoker, in outpatient follow-up with pneumology due to chronic obstructive pulmonary disease, using tiotropium bromide $2.5 \mathrm{mcg}$ twice a day. History of recurrent syncope in the last month that had already happened in supine position and also during physical effort. No complaints of dyspnea, chest pain or palpitations preceding syncope She denied a family history of sudden death. She was referred to hospital for investigation of syncope after clinical evaluation and risk score (EGSYS 5 score) show high probability of cardiac etiology.

Among the investigation tests, she presented an electrocardiogram in sinus rhythm and QTc interval of $410 \mathrm{~ms}$, laboratory with potassium $4.2 \mathrm{mg} / \mathrm{dL}(3.5-5.5 \mathrm{mg} / \mathrm{dL})$, magnesium $2.1 \mathrm{mg} / \mathrm{dL}(1.7-2.6 \mathrm{mg} / \mathrm{dL})$ and ionic calcium $5.0 \mathrm{mg} / \mathrm{dL}$ (4.6-5.4 mg/dL). A transthoracic echocardiogram was performed with the left atrium with slight volume increase, grade I diastolic dysfunction, preserved systolic function and no change in segmental contractility.

Electrocardiographic monitoring with 24-hour Holter (H24) (CardioScan II, DM Software, USA) was installed on the first day of hospitalization. The recording started at $17 \mathrm{~h}$ in sinus rhythm, with a heart rate of approximately $60 \mathrm{bpm}$ and a QTc interval of $440 \mathrm{~ms}$ (Fig, 1a). After 20 min of recording, the patient presented an unevenness of the ST segment and Mobitz 2 atrioventricular block (AVB) (Fig. 1b), followed by AVB 2:1 (Fig. 1c) and evolution to total paroxysmal AVB (Fig. 1d) interrupted by atrial tachycardia rhythm (Fig. 2a).

About 1 min after maintenance of atrial tachycardia rhythm, she showed evolution to torsades de pointes (Fig. 2b and c) that rapidly evolved to ventricular fibrillation
(Fig. 2d). After recording approximately $1 \mathrm{~min}$ of the onset of ventricular fibrillation, the $\mathrm{H} 24$ was removed and cardiopulmonary resuscitation maneuvers with defibrillation, cardiac massage and anti-arrhythmic drugs were initiated, however the patient evolved to asystole and after 40 min of resuscitation, she was declared dead.

\section{DISCUSSION}

The H24 is a tool that can provide definitive information on electrical events that precede arrhythmias leading to the SCD. It is estimated that the primary event that initiates the events that determine MSC to H24 rarely occurs due to bradyarrhythmias and especially ventricular arrhythmias, which include monomorphic or polymorphic ventricular tachycardia (VT) and ventricular fibrillation ${ }^{1-3}$.

In the largest series of cases, Bayés de Luna et al., in a study with 157 cases of SCD to H24, observed that bradyarrhythmias are responsible for the sequence of events that trigger SCD in less than $20 \%$ of the cases, as described in this report. Typically, when they occur, they are associated with advanced age and higher frequency of comorbidities compared to patients with SCD related to ventricular arrhythmias ${ }^{1}$.

Primary ventricular arrhythmias were responsible for $83.4 \%$ of the cases of death during monitoring with $\mathrm{H} 24$ and the most frequent rhythm was monomorphic VT, followed by torsades of points (TdP) and ventricular fibrillation ${ }^{1}$.

The compensatory mechanisms that occur in a sudden bradycardia can lead to several types of tachyarrhythmias ${ }^{3-5}$. In this report, the AVB led to the episode of atrial tachycardia followed by TdP, which culminated with the final event of ventricular fibrillation.

The TdP is a classic polymorphic VT described since 1966 with typical morphology due to changes in QRS amplitude and polarity preceded by coupling $>500 \mathrm{~ms}$ in a long QT scenario. In 1994, Leenhardt et al. described a variant of TPt that occurred at normal $\mathrm{QT}$ intervals, but started within the sinus rhythm by extrasystole with a short coupling interval around 200 to $300 \mathrm{~ms}^{6,7}$.

The presentation of TdP in the record of this report, preceded by atrial tachycardia, may be justified by sudden bradycardia generated by paroxysmal AVB and probable reflex 


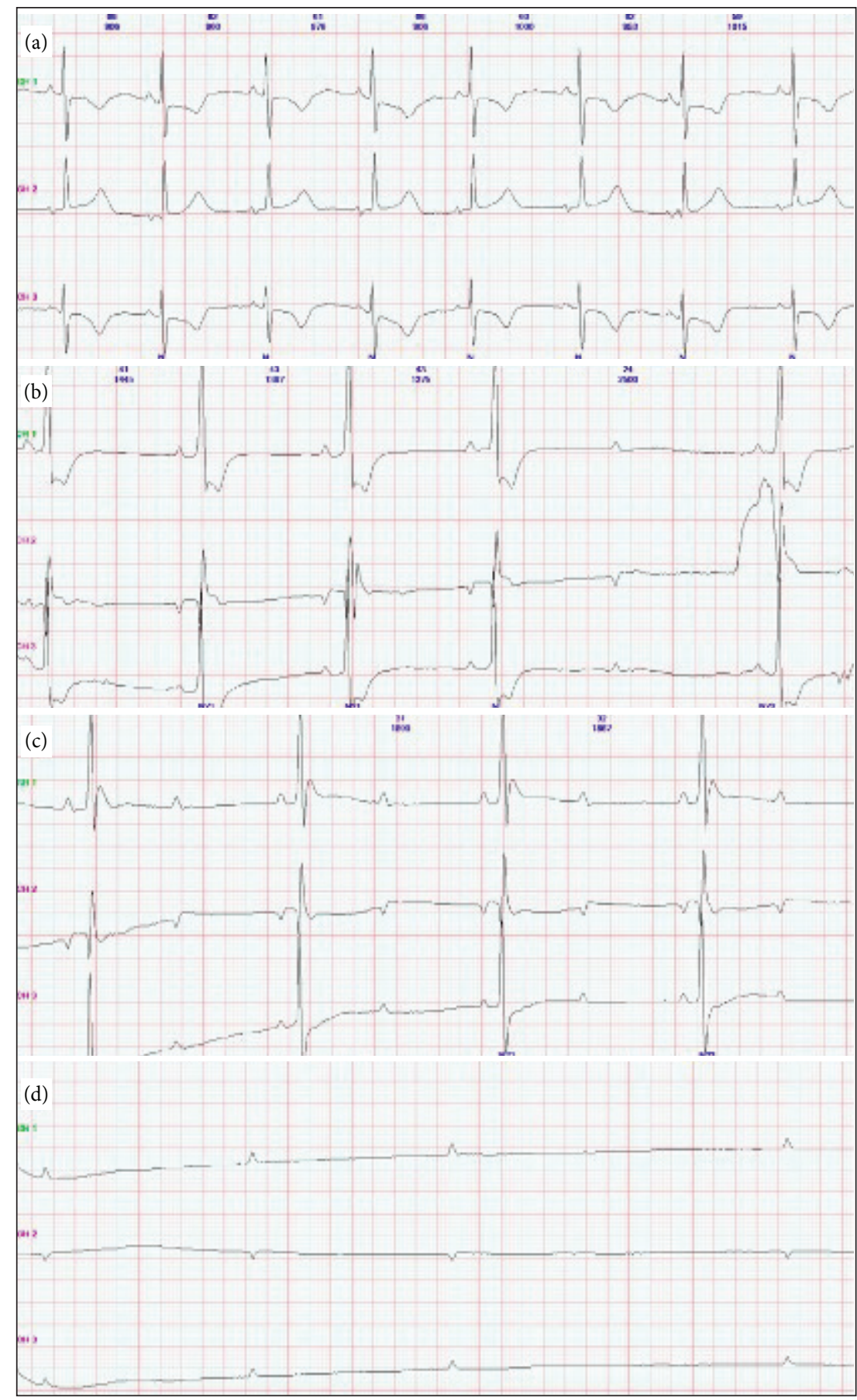

Figure 1. Electrocardiographic monitoring.

mechanism with increase of circulating catecholamines and increase of calcium inflow in phase 2 of action potentia ${ }^{3-5}$. The $\mathrm{TdP}$ can be self-limited, however, because it is an arrhythmia with high and disorganized ventricular response, in cases where it occurs in a sustained manner, there is evolution to ventricular fibrillation ${ }^{1}$, as in this report.

Alterations in the ST segment before fatal arrhythmias in $\mathrm{H} 24$ can be found in 10 to $30 \%$ of cases, mainly when the primary arrhythmia is a polymorphic VT or ventricular fibrillation, suggesting that myocardial ischemia may play a role in the SCD of these patients ${ }^{1,2}$.

The patient in this report presented an unevenness of the ST segment that preceded the AVB appearance, however, despite risk factors for atherosclerotic disease, it was not possible to obtain data proving the ischemic origin of paroxysmal AVB.

Some studies ${ }^{1,8-10}$ tried to correlate a circadian periodicity from the time of SCD to $\mathrm{H} 24$ and observed a peak incidence 


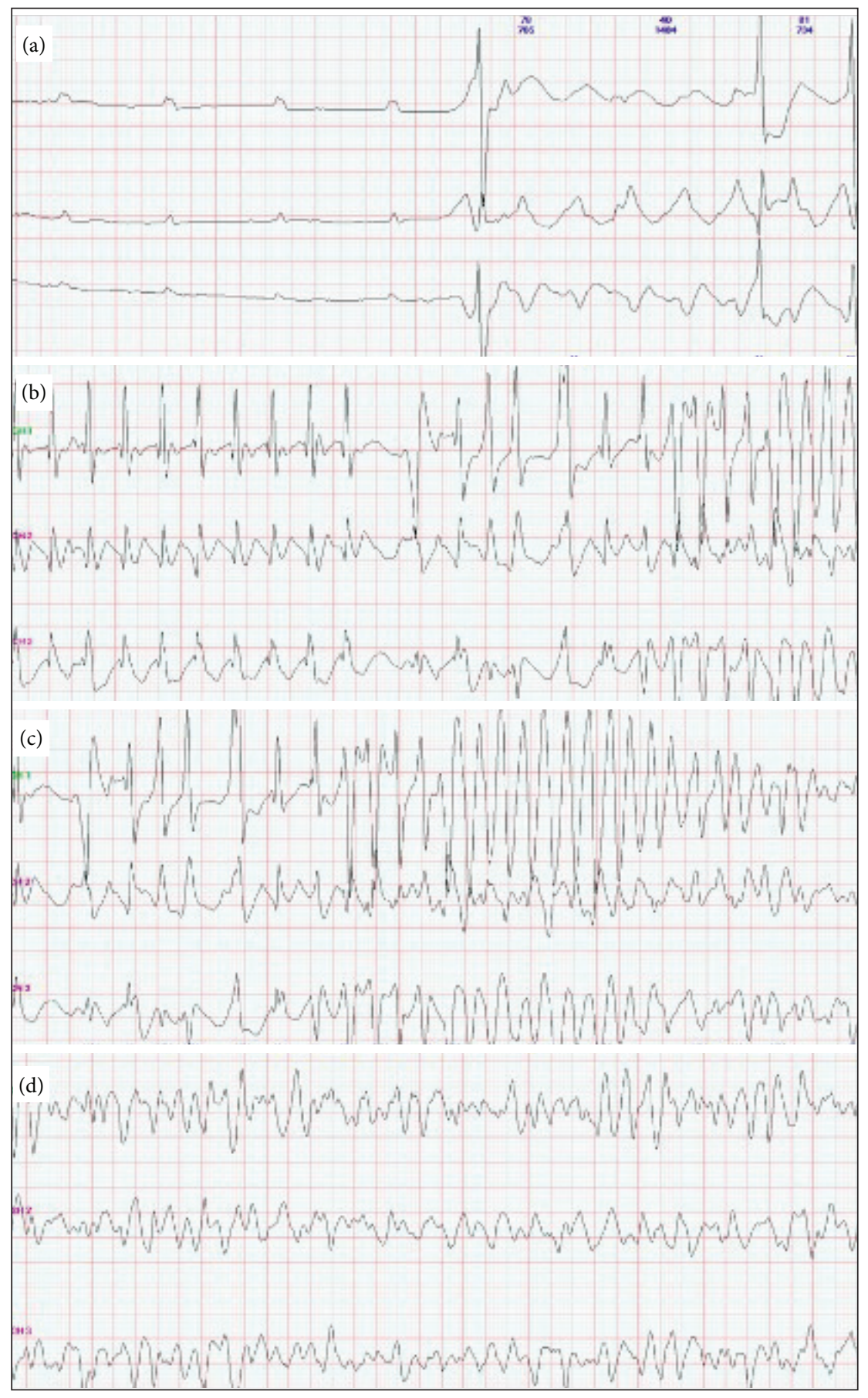

Figure 2. Electrocardiographic monitoring.

in the early morning hours. The highest incidence of SCD in this period of the day occurred mainly in patients with the initial event being polymorphic VT or ventricular fibrillation, which may be related to the periodicity of ischemic events which is known to be higher in the first hours of the morning ${ }^{1,8}$.

The nocturnal predominance of SCD was observed in a group of patients in which the initial event that triggered the SCD was TdP, possibly linked to some channelopathies that may have the vagal period as trigger ${ }^{1}$.

In this case, the sequence of arrhythmic mechanisms that culminated in SCD during monitoring with $\mathrm{H} 24$ was described, an event barely reported in the literature, especially when the initial event is a bradycardia. In this case, atrioventricular block was initially observed followed by atrial tachycardia, TdP and finally ventricular fibrillation with evolution to SCD. 


\section{REFERENCES}

1. Bayés de Luna A, Coumel P, Leclercq JF. Ambulatory sudden cardiac death: Mechanisms of production of fatal arrhythmia on the basis of data from 157 cases. Am Heart J. 1989;117(1):151-9. https://doi.org/10.1016/00028703(89)90670-4

2. Watanabe E, Tanabe T, Osaka M, Chishaki A, Takase B, Niwano S, et al. Sudden cardiac arrest recorded during Holter monitoring: prevalence, antecedent electrical events, and outcomes. Heart Rhythm. 2014;11(8):1418-25. https:// doi.org/10.1016/j.hrthm.2014.04.036

3. Huikuri HV, Castellanos A, Myerburg RJ. Sudden death due to cardiac arrhythmias. N Engl J Med. 2001;345(20):147382. https://doi.org/10.1056/NEJMra000650

4. Hamaguchi E, Kawano H, Kawahito S, Kitahata H, Oshita S. Torsades de pointes associated with severe bradycardia after induction of general anesthesia. Masui. 2011;60(9):1097100.

5. Chorin E, Hochstadt A, Viskin S, Rozovski U, Havakuk O, Baranchuk A, et al. Female gender as independent risk factor of torsades de pointes during acquired atrioventricular block. Heart Rhythm. 2017;14(1):90-5. https://doi.org/10.1016/j. hrthm.2016.09.013
6. Leenhardt A, Glaser E, Burguera M, Nürnberg M, MaisonBlanche P, Coumel P. Short-coupled variant of torsade de pointes: a new electrocardiographic entity in the spectrum of idiopathic ventricular tachyarrhythmias. Circulation. 1994;89(1):206-15. https://doi.org/10.1161/01.cir.89.1.206

7. Chokr MO, Darrieux FCC, Hardy CA, Hachul DT, Britto AVO, Melo SL, et al. Short-coupled variant of "torsade de pointes" and polymorphic ventricular tachycardia. Arq Bras Cardiol. 2014;102(6):e60-4. https://doi.org/10.5935/abc.20140075

8. Thosar SS, Butler MP, Shea SA. Role of the circadian system in cardiovascular disease. J Clin Invest. 2018;128(6):215767. https://doi.org/10.1172/JCl80590

9. Black N, D'Souza A, Wang Y, Piggins H, Dobrzynski H, Morris $\mathrm{G}$, et al. Circadian rhythm of cardiac electrophysiology, arrhythmogenesis, and the underlying mechanisms. Heart Rhythm. 2019;16(2):298-307. https://doi.org/10.1016\%2Fj. hrthm.2018.08.026

10. Takeda N, Maemura K. Circadian clock and the onset of cardiovascular events. Hypertens Res. 2016;39(6):383-90. https://doi.org/10.1038/hr.2016.9 